\title{
Transcatheter rectal arterial chemoembolization with oxaliplatin plus $S$ - 1 concurrent chemoradiotherapy can improve the pathological remission rate in locally advanced rectal cancer: a comparative study
}

Bo Yang ${ }^{1}$, Jinlu Shan ${ }^{1}$, Yan Feng ${ }^{1}$, Nan Dai ${ }^{1}$, Mengxia Li ${ }^{1}$, Chuan Chen ${ }^{1}$, Shengyong He ${ }^{1}$, Ge Wang ${ }^{1}$, Hualiang Xiao ${ }^{2}$, Chunxue $\mathrm{Li}^{3^{*}}$ and Dong Wang ${ }^{1^{*}}$

\begin{abstract}
Background: To explore the efficacy and safety of Transcatheter rectal arterial chemoembolization with oxaliplatin and S-1 concurrent chemoradiotherapy as neoadjuvant therapy for locally advanced rectal cancer.

Methods: This s a prospective, monocentric, non-randomized clinical study, a total of 95 patients were enrolled and assigned to two groups: an investigational group $(n=50)$ receiving transcatheter rectal arterial chemoembolization (TRACE) with oxaliplatin and preoperative radiotherapy plus S-1 concurrent chemotherapy (NATRACE-CRT), followed by surgery, a control group $(n=45)$ receiving standard fluorouracil-based combined modality treatment, consisting of preoperative radiotherapy plus capecitabine based chemotherapy (NA-CRT), followed by surgery. The primary endpoint was postoperative pathological regression rate which evaluated by tumor regression grade (TRG) according to the 7th edition of the American Joint Committee on Cancer (AJCC) standard, and the secondary endpoints included objective response rate (ORR) and toxicity, as well as surgical complications, and postoperative tumor downstaging.

(Continued on next page)
\end{abstract}

\footnotetext{
* Correspondence: 1823889736@qq.com; dongwang64@hotmail.com ${ }^{3}$ Department of General Surgery, Colorectal Division, Daping Hospital \& Army Medical Center of PLA, Third Military Medical University (Army Medical University), Chongqing 400042, China

${ }^{1}$ Cancer Center, Daping Hospital \& Army Medical Center of PLA, Third Military Medical University (Army Medical University), Chongqing 400042,

China

Full list of author information is available at the end of the article
}

(c) The Author(s). 2020 Open Access This article is licensed under a Creative Commons Attribution 4.0 International License, which permits use, sharing, adaptation, distribution and reproduction in any medium or format, as long as you give appropriate credit to the original author(s) and the source, provide a link to the Creative Commons licence, and indicate if changes were made. The images or other third party material in this article are included in the article's Creative Commons licence, unless indicated otherwise in a credit line to the material. If material is not included in the article's Creative Commons licence and your intended use is not permitted by statutory regulation or exceeds the permitted use, you will need to obtain permission directly from the copyright holder. To view a copy of this licence, visit http://creativecommons.org/licenses/by/4.0/ The Creative Commons Public Domain Dedication waiver (http://creativecommons.org/publicdomain/zero/1.0/) applies to the data made available in this article, unless otherwise stated in a credit line to the data. 


\begin{abstract}
(Continued from previous page)
Results: Compared with NA-CRT group (17.78\% (95\% confidence interval (Cl): 6.2-29.4)), the TRG0 was 30\% (95\% Cl 16.8-43.2) in the NATRACE-CRT group ( $P=0.231)$. The TRG0 + 1 rate was $60 \%$ (95\% Cl: 45.9-74.1) and 33.33\% (95\% Cl: 19-47.7) in NATRACE-CRT group and NA-CRT group, respectively $(P=0.013)$. The ORR of the NATRACE-CRT group was $84 \%$ and that of the NA-CRT group was $66.67 \%(p=0.058)$. Incidence of preoperative toxic side effects and surgical complications was similar between the two groups.
\end{abstract}

Conclusion: TRACE with oxaliplatin plus concurrent S-1 chemoradiotherapy as a neoadjuvant therapy provided better pathological remission rate versus standard treatment with a similar safety profile.

Trial registration: NCT03601156.

Keywords: Rectal cancer, Chemoembolization, S-1, Neoadjuvant chemoradiotherapy, Clinical study

\section{Background}

The incidence and mortality of colorectal cancer are gradually increasing in China [1]. China's cancer statistics showed that the ranks of incidence and mortality of colorectal cancer were the third and the second among all malignant tumors, respectively, of which rectal cancer accounted for about 28\% [2]. Combined-modality therapy consisting of preoperative chemoradiotherapy (CRT), total mesorectal excision (TME) surgery, and postoperative chemotherapy have become standard treatment models for locally advanced rectal cancer (LARC) [3, 4]. Neoadjuvant chemoradiotherapy can improve the rate of local control and organ preservation, while pCR (pathologic complete remission) only can be achieved in a small number of patients $[5,6]$. The majority of studies have revealed that the pCR rate after neoadjuvant therapy is about 10-25\% [7], which has been hovering at a low level, regardless of the change of radiotherapy mode or chemotherapy regimen [8].

It has been reported that $\mathrm{pCR}$, as a therapeutic response of neoadjuvant radiation response, is an independent predictor of disease-free survival (DFS) and overall survival (OS) [9]. Studies have shown that the 5year survival rate of pCR patients is $92.6 \%$ and that of non-pCR patients is only $73.1 \%$ [10].

Transcatheter rectal arterial chemoembolization (TRACE) aims to control the tumor by injecting a single or multiple chemotherapeutic agents after the selective catheterization of the tumor feeding artery, thereby embolizing the tumor feeding artery [11]. At present, TRACE has been extensively used in the treatment of primary liver carcinoma and metastatic liver tumor [12], Roberto Bini runed a prospective mono-institutional study of TRACE-Debiri as an exclusive treatment for locally advanced rectal cancer not suitable for any further treatment option, and they found TRACE with Debiri could be a possible option for locally advanced/inoperable or recurred rectal cancer patients [13].

S-1 combines tegafur, gimeracil, and oteracil potassium in a molar ratio of 1:0.4:1. In JFMC35-C1: ACTS$\mathrm{RC}$ trial, the researchers compared the efficacy of S-1 and tegafur-uracil in adjuvant therapy after curative surgery in LARC. The results showed that S-1 was superior to tegafur-uracil in 5-year RFS, with an increase of $4.7 \%$ in 5-year RFS, but there was no significant difference in 5-year OS between the two groups, and the side effects of the two groups were similar [14]. In addition, JACCRO CC-04: SHOGUN trial has been found that S-1, as neoadjuvant chemotherapy in LARC, can improve the pCR rate [15].

To explore the efficacy and safety of TRACE with oxaliplatin and S-1 concurrent chemoradiotherapy as neoadjuvant therapy for locally advanced rectal cancer. We designed this study and compared the efficacy and safety of this treatment regimen and 5-FU-based neoadjuvant chemoradiotherapy for LARC.

\section{Methods \\ Patients}

This is a prospective, non-randomized clinical study, and that was approved by the Ethics Committee of our university (Clinical Trial No. NCT03601156). Each patient signed the written informed consent form prior to start of the study.

Inclusion criteria were as follows: (1) age, 18-75 years old; (2) pathological diagnosis of rectal adenocarcinoma by rectosigmoidoscopy; (3) clinical diagnosis (magnetic resonance imaging (MRI)) of T3-4, any N; (4) distance between the tumor and anal margin $<12 \mathrm{~cm}$; (5) Eastern Cooperative Oncology Group (ECOG) score of performance status $\leq 1$. Exclusion criteria were as follows: (1) distant metastasis was found by preoperative examination; (2) with other serious complications cannot complete treatment regimen, such as a surgical contraindication; (3) patients with a history of radiotherapy or chemotherapy.

According to the inclusion and exclusion criteria, 112 patients were recruited from our hospital from August 2015 to August 2018. Seventeen patients who did not complete NCRT and operation as planned were removed (7 in NATRACE-CRT group, 10 in NA-CRT group), Finally, 95 patients were divided into NATRACE-CRT 
group and NA-CRT group according to patient wishes, including 50 cases in the NATRACE-CRT group and 45 patients in the NA-CRT group (Fig. 1 shows the patients' recruitment and treatment schema).

\section{Treatment regimen}

For TRACE in the NATRACE-CRT group, conventional femoral artery puncture and catheterization as well as angiography were conducted by Seldinger technique. Next, superselective catheterization of the superior rectal artery and inferior rectal artery was performed (to identify the primary tumor feeding arteries), in which the superselective catheters were inserted to each thickening and tortuous artery of the tumor lesions using a microcatheter. Subsequently, according to body-surface area $\left(85 \mathrm{mg} / \mathrm{m}^{2}\right)$, Oxaliplatin (Jiangsu Hengrui Medicine Co. Ltd., Nanjing, China) diluted to $50 \mathrm{ml}$ normal saline was slowly infused (10 mins) via the transcatheter, after that the superior rectal artery was embolized using Gelatin Sponge Particle Embolic Agent (350-560 $\mu \mathrm{m}$; Alicon Hangzhou, China) and $15 \mathrm{ml}$ of Iodixanol, followed by angiography to confirm the embolism status. (In order to avoid tissue necrosis caused by simultaneous embolization of the superior rectal artery and the inferior rectal artery, we only selectively embolized the superior rectal artery.) The end-point of the embolization was the stagnation of blood flow in the feeding arteries conformed by angiography (Fig. 2). All operations were performed by the same interventional physician (He SY) as well.
In NATRACE-CRT group, S-1 (Taiho Pharmaceutical Company, Tokyo, Japan) was oral administered after arterial chemoembolization according to body-surface area (BSA), dose and times of administration as: $\mathrm{BSA}<1.2$ $\mathrm{m}^{2}: \quad 80 \mathrm{mg}, \quad 2 /$ day; $\quad \mathrm{BSA}=1.2-1.5 \mathrm{~m}^{2}: 100 \mathrm{mg}, 2 /$ day; BSA $>1.5 \mathrm{~m}^{2}: 120 \mathrm{mg} /$ day, 2/day, $7 \mathrm{~d} /$ week; on day 1 to day 28 , and stop taking it for 14 days.

In the NA-CRT group, Patients received capecitabine during the radiotherapy, dose, and times of administration as: capecitabine (Shanghai Roche Pharmaceutical Co. Ltd., Shanghai, China) according to BSA (825 mg/ $\mathrm{m}^{2}$ ), 2/day, $5 \mathrm{~d} /$ week; on day 1 to day 35 .

Both two groups received radiotherapy which delivered using a 4-field conformal coplanar technique (anteroposterior, posteroanterior, right lateral and left lateral fields) and 6-8 MV photon beams. A total dose of $45 \mathrm{~Gy}$ was given in $1.8 \mathrm{~Gy}$ fractions, five fractions per week, lasting for a total of 5 weeks.

Radical resection of rectal cancer was performed 4 weeks after completion of chemoradiotherapy. The principle of operation was total mesorectal excision, and sigmoid colostomy or ileostomy was routinely undertaken. Stoma closure was also carried out 6 months after surgery.

Although adjuvant treatment was not part a of the present study, however, following the National Comprehensive Cancer Network (NCCN) guidelines, adjuvant chemotherapy was recommended for all patients regardless of histology (i.e., in case of pathologic complete remission). Treatment was recommended to be followed for 4 to 6 months using mFOLFOX6 or CapeOx regimen.

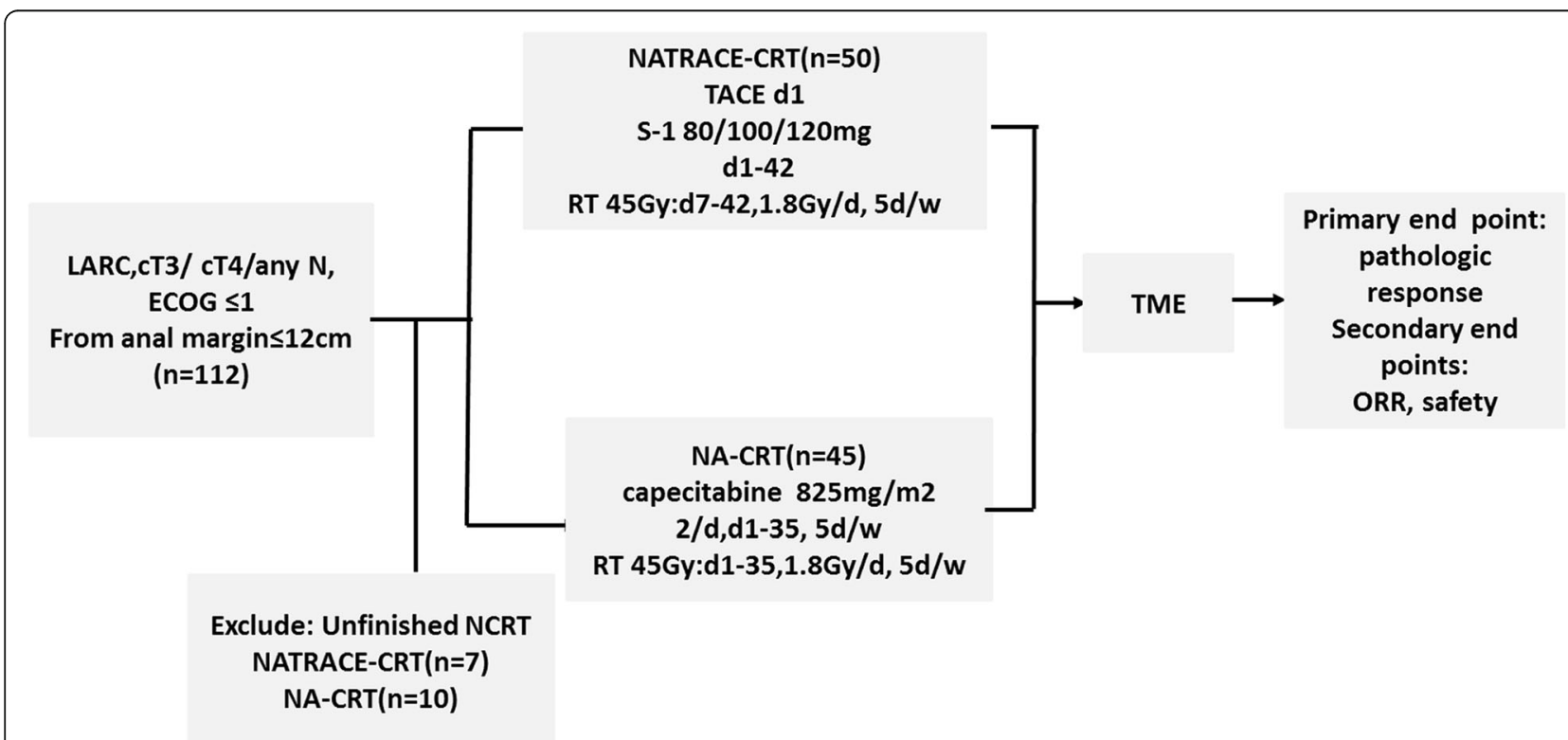

Fig. 1 The study diagram. After enrollment, 17 patients were not included in the final analysis due to the absence of surgery (8) and incomplete chemoradiotherapy (9) respectively 

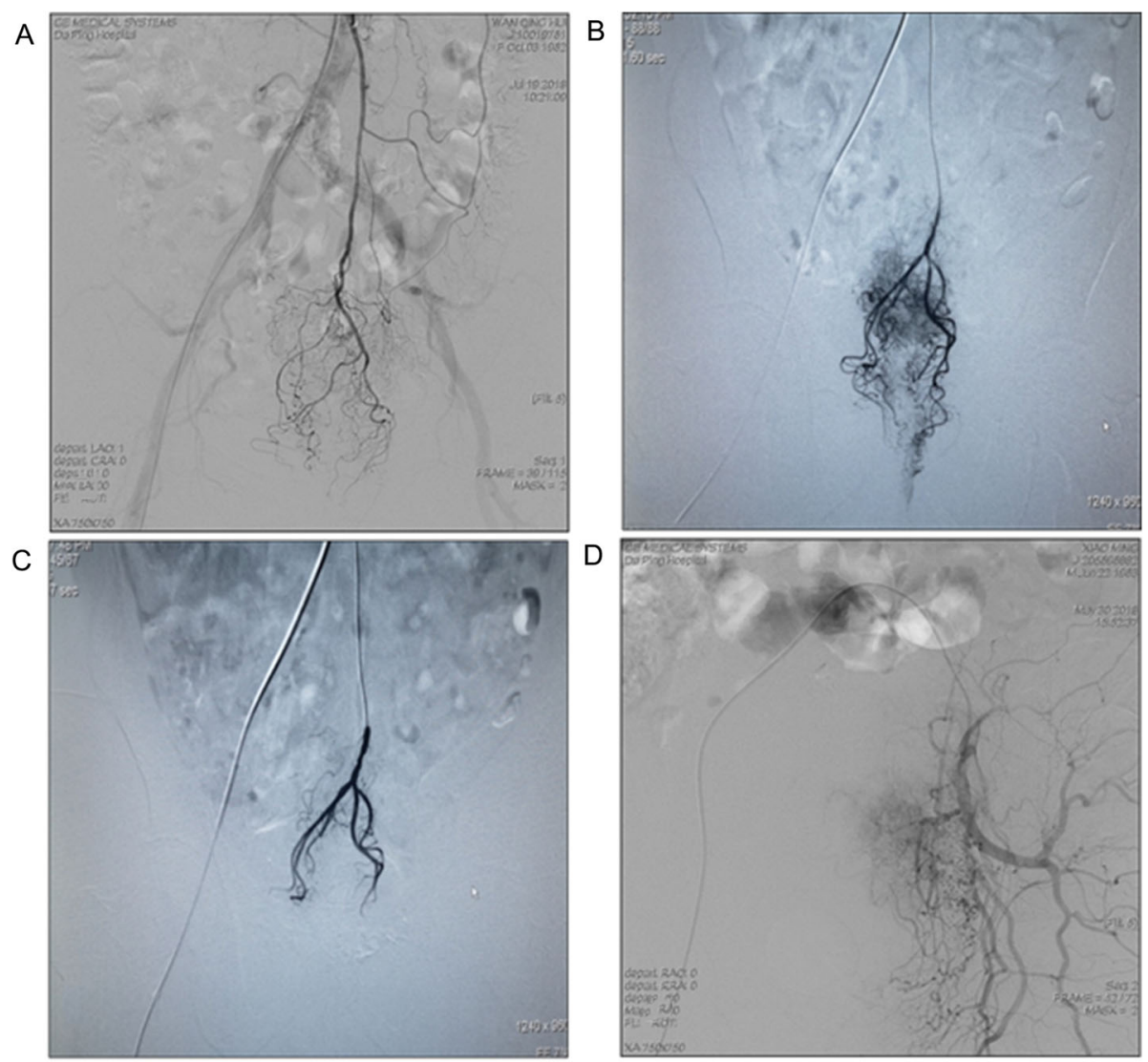

Fig. 2 a-d shows the process of TRACE. a Frontal inferior mesenteric arteriogram shows a minimal hypervascular blush in the rectum. $\mathbf{b}$ Frontal selective superior rectal arteriogram shows a hypervascular blush within the rectum. c Frontal superior rectal arteriogram after TRACE shows no hypervascular blush with pruning of the arterial supply to the rectal tumor. $\mathbf{d}$ shows angiogram of the internal iliac artery

Patients were followed up according to NCCN guidelines, history and physical every 3-6 months for 2 years, then every 6 months for a total of 5 years;CEA every 3 months for 2 years then every 6 months for a total 5 years;chest and abdominal/pelvic CT every 6 months for 2 years, then 12 months for a total 5 years.

\section{Evaluation of safety and efficacy}

The assessment of clinical efficacy was performed by MRI according to the RECIST (Response Evaluation Criteria In Solid Tumors) 1.1 criteria [16]: complete remission $(\mathrm{CR})$, disappearance of all target lesions; partial remission (PR), at least 30\% decrease in the sum of diameters of target lesions; progression of disease (PD), at least $20 \%$ increase in the sum of diameters of target lesions or appearance of one or more new lesions; stable disease (SD), neither sufficient shrinkage to qualify PR nor sufficient increase to qualify PD; besides, objective response rate (ORR) was calculated by $\mathrm{CR}+\mathrm{PR}$.

Tumor regression grade (TRG) was assessed according to the 7th edition of the American Joint Committee on Cancer (AJCC) standard [17]. TRG0 showed CR without residual tumor cells; TRG1 demonstrated a better response with only a single or very few residual tumor cells; TRG2 showed less response to tumors and still had residual tumor cells; TRG3 indicated a poor response to tumors, in which few or no tumor cells were killed (Fig. 3). The rectum was cut into transverse sections according to the Quirke procedure [18], and the TRG assessment was performed by two independent pathologists (DW, HL X).

Evaluation procedures, including physical examinations, measurement of vital signs, and complete blood count test, were performed weekly during neoadjuvant treatment. Toxicity was assessed and graded according to the Common Terminology Criteria for Adverse Events (CTCAE; version 4.0) issued by the National Cancer Institute.

\section{Study endpoints and statistical analysis}

The primary endpoint is the pathological remission rate. The secondary endpoints include ORR and toxicity, as well as surgical complications and tumor downstaging. 

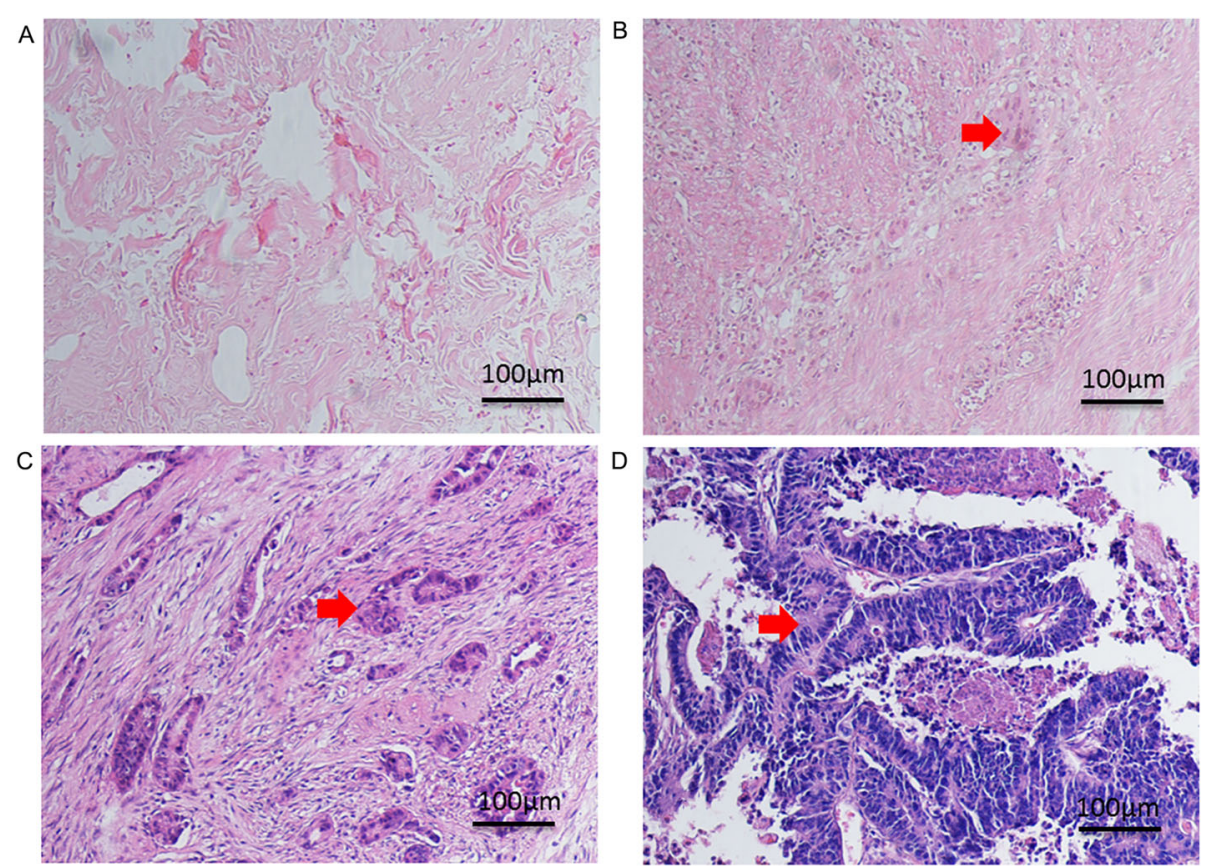

Fig. 3 a-d shows different pathological findings of neoadjuvant therapy. HE staining of TRG0-3 grade (AJCC standard), respectively (h\&e, original magnification $=\times 20$, Bar scale $=100 \mu \mathrm{m})$, the arrows indicate residual tumor cells. a It shows TRG0 $(p C R)$ complete remission without residual tumor cells; b. It displays TRG1 with only a single or few residual tumor cells; $\mathbf{c}$. It shows less response to tumors with residual tumor cells; $\mathbf{d}$. It shows TRG3 poor response to tumors, in which few or no tumor cells were killed. Arrows shows tumor cells

Data were statistically analyzed by using SPSS 23.0 software (IBM, Armonk, NY, USA). The measured data were expressed as $\mathrm{x} \pm \mathrm{s}$ or mean (range), reflecting normal distribution of data,; besides, the independent sample $t$-test was used, demonstrating the non-normal distribution of data; the count data were expressed by the rate (\%), and the Chi-square test was used as well. $P<0.05$ was considered statistically significant. Cumulative survival probabilities were estimated using the Kaplan-Meier method, and differences between survival rates were tested for significance using the log-rank test.

\section{Results}

\section{Patient characteristics}

Patients' characteristics are detailed in Table 1. The median age of the NATRACE-CRT group and NA-CRT group was 62 years (range, 20-75 years) and 57 (range, 32-75 years), respectively, and males accounted for 70.00 and $75.56 \%$ of the patients, respectively. There were 35 and 24 patients in stage of cT3, and the number of node positive cases was 36 and 27 in NATRACE-CRT group and NA-CRT group, respectively. In the NATR ACE-CRT group, there were 15 cases in which tumors had a distance of more than $5 \mathrm{~cm}$ from the anal margin, and 17 cases were also found in the NA-CRT group. There was no significant difference in the demographic and disease characteristics of the two groups.

\section{Treatment exposure}

One patient in the NATRACE-CRT group received irinotecan and bevacizumab for tumor progression during concurrent chemoradiotherapy. The rest of the patients were treated as planned.

The cumulative dose of radiotherapy in the NATR ACE-CRT group and NA-CRT group was $41.28 \pm 4.49$ and $44.38 \pm 5.35$ Gy, respectively.

\section{Efficacy \\ Clinical response}

Preoperative imaging examination revealed that $7 \mathrm{pa}$ tients in the NATRACE-CRT group achieved CR, and 35 patients achieved PR, while 4 and 26 patients in the NA-CRT group achieved CR and PR, respectively. The ORR of the NATRACE-CRT group was $84 \%$ and that in the NA-CRT group was $66.67 \%$, indicating that the ORR of the NATRACE-CRT group was higher than that in the NA-CRT group $(P=0.058)$. There was also no statistical significance between the two groups (Table 2).

In addition, 26 patients in the NATRACE-CRT group achieved a downstaging of T-stage, 26 patients achieved a downstaging of $\mathrm{N}$-stage, and 31 of the 50 patients finally reached $\mathrm{T}$ or $\mathrm{N}$ downstaging. In the NA-CRT group, there were 17 cases with downstaging of T-stage and 16 cases with downstaging of $\mathrm{N}$-stage, in which 22 patients reached $\mathrm{T}$ or $\mathrm{N}$ downstaging. The downstaging 
Table 1 Demographic characteristics of the patients

\begin{tabular}{|c|c|c|c|}
\hline Characteristic & NATRACE-CRT N & NA-CRT N & $P$-value \\
\hline \multicolumn{4}{|l|}{ Gender (\%) } \\
\hline Male & $35(70.00)$ & $34(75.56)$ & 0.647 \\
\hline Female & $15(30.00)$ & $11(24.44)$ & \\
\hline \multicolumn{4}{|l|}{ Age (years) } \\
\hline Median & 62 & 57 & 0.063 \\
\hline Range & $20-75$ & $32-75$ & \\
\hline \multicolumn{4}{|l|}{ ECOG performance status (\%) } \\
\hline 0 & $43(86.00)$ & $37(82.22)$ & 0.784 \\
\hline 1 & $7(14.00)$ & $8(17.78)$ & \\
\hline \multicolumn{4}{|l|}{ BMI $\left(\mathrm{kg} / \mathrm{m}^{2}\right)$} \\
\hline Mean & $22.71 \pm 3.07$ & $24.18 \pm 2.97$ & 0.024 \\
\hline \multicolumn{4}{|l|}{ Tumor length (mm) } \\
\hline Mean & $4.15 \pm 1.85$ & $3.94 \pm 1.31$ & 0.293 \\
\hline \multicolumn{4}{|l|}{ Distance from the $A V(\mathrm{~cm})$} \\
\hline Mean & $6.1 \pm 2.63$ & $5.73 \pm 2.84$ & NA \\
\hline$<5$ & $15(30.00)$ & $17(37.78)$ & \\
\hline$\geq 5$ & $35(70.00)$ & $28(62.22)$ & \\
\hline \multicolumn{4}{|l|}{ Clinical T stage } \\
\hline T3 & $35(70.00)$ & $24(53.33)$ & 0.138 \\
\hline T4 & $15(30.00)$ & $21(46.67)$ & \\
\hline \multicolumn{4}{|l|}{ Clinical N stage } \\
\hline No & $14(28.00)$ & $18(40.00)$ & 0.455 \\
\hline N1 & $19(38.00)$ & $15(33.33)$ & \\
\hline N2 & $17(34.00)$ & $12(26.67)$ & \\
\hline \multicolumn{4}{|l|}{ Baseline CEA level (ng/ml) } \\
\hline Median & 2.88 & 3.29 & 0.516 \\
\hline Range & $0.48-63.75$ & $0.42-135.82$ & \\
\hline$\leq 5.0$ & $35(70.00)$ & $28(62.22)$ & \\
\hline$>5.0$ & $15(30.00)$ & $17(37.78)$ & \\
\hline \multicolumn{4}{|l|}{ Histological grade } \\
\hline Well differentiated & $6(12.00)$ & $6(13.34)$ & 0.979 \\
\hline Moderately differentiated & $29(58.00)$ & $26(57.78)$ & \\
\hline Poorly differentiated & $15(30.00)$ & $13(28.88)$ & \\
\hline
\end{tabular}

Abbreviations: ECOG Eastern Cooperative Oncology Group, BMI body mass index, $A V$ anal verge, CEA carcinoembryonic antigen

rates of the two groups were 62 and $48.89 \%$, respectively $(P=0.22)$ (Table S1).

\section{Surgery-related outcomes}

In the NATRACE-CRT group, 50 patients underwent radical resection of rectal cancer, including 40 cases with low anterior resection, 9 cases with abdominal perineal resection, 1 case with total pelvic organ resection, and 50 cases with routine sigmoid colostomy. Only 1 patient underwent $\mathrm{R} 1$ resection and the remaining underwent $\mathrm{R} 0$ resection. All the patients achieved a negative
Table 2 Objective Tumor Responses by Imaging

\begin{tabular}{lll}
\hline Response & $\begin{array}{l}\text { After NATRACE-CRT } \\
(n=50)\end{array}$ & $\begin{array}{l}\text { After NA-CRT } \\
(n=45)\end{array}$ \\
& No. of Patients (\%) & No. of Patients (\%) \\
\hline Complete response & $7(14.00)$ & $4(8.89)$ \\
Partial response & $35(70.00)$ & $26(57.78)$ \\
Stable disease & $7(14.00)$ & $15(33.33)$ \\
Progressive disease & $1(2.00)$ & $0(0)$ \\
Objective response rate, \% & $42(84.00)$ & $30(66.67)$ \\
95\% Cl & $73.5-94.5 \%$ & $52.3-81 \%$ \\
$\mathbf{P}$ value & 0.058 & \\
\hline
\end{tabular}

circumferential margin (tumor distance $>1 \mathrm{~mm}$ ). In the NA-CRT group, 30 cases were treated with low anterior resection, 13 cases with abdominal perineal resection, 2 cases with total pelvic organ resection, 45 cases with conventional sigmoid colostomy, and 45 cases achieved $\mathrm{R} 0$ resection and circumferential margin negative Table S2.

\section{Pathological response}

Tumor regression grade was assessed according to the AJCC criteria, of 95 cases of surgical resection specimens, there were 15 cases of TRG0 (pCR), 15 cases of TRG1, 13 cases of TRG2, and 7 cases of TRG3 in NATR ACE-CRT group, while 8 cases of TRG0 (pCR), 7 cases of TRG1, 17 cases TRG2, and 13 cases of TRG3 were found in the NA-CRT group (Fig. 4a). The pCR rate in the NATRACE-CRT group was 30\% (95\% confidence interval (CI): $16.8-43.2$ ) and $17.78 \%$ (95\% CI: 6.2-29.4) in the NA-CRT group $(P=0.231)$, respectively. Although there was no statistical difference in $\mathrm{pCR}$ rate between the two groups, however, the TRG0 +1 rate in the two groups was 60\% (95\% CI: 45.9-74.1) and 33.33\% (95\% CI: 19-47.7), respectively, which showed a remarkable difference $(P=0.013)$ (Fig. $4 \mathrm{~b})$. This result demonstrated that tumor regression rate of the NATRACE-CRT group was significantly higher than that of the NA-CRT group.

The follow-up time of NATRACE-CRT group was 760 months, and the median follow-up time was 33 months, the NA-CRT group was 4-60 months, and the median follow-up time was 27 months. We analyzed the DFS of the two groups. There was no statistical difference between the two groups (Fig. 4c). The median DFS of the two groups was not reached. The DFS rates of the two groups in 1 year and 3 years were $88 \%$ vs.92, $76 \%$ vs. $58 \%, P=0.0797$.

\section{Toxicity}

TRACE and Chemoradiotherapy-related toxicity

The occurrence of adverse events in the NATRACECRT group and the NA-CRT group was similar; for example, adverse events of grade 3-4, including 

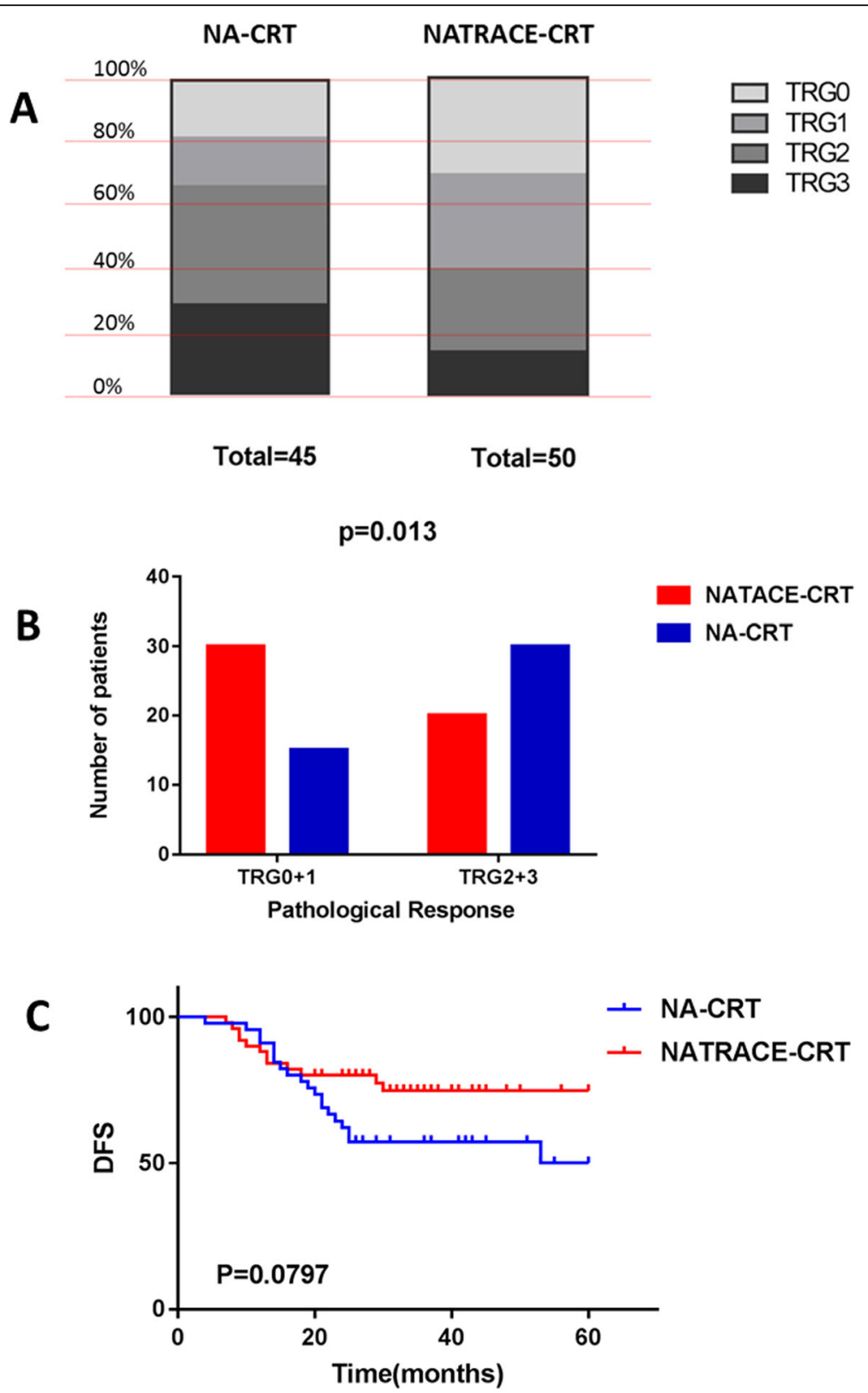

Fig. 4 Pathological response rate and DFS. a It displays the tumor pathological regression graded in each group. There were 15 cases of TRGO (pCR), 15 cases of TRG1, 13 cases of TRG2, and 7 cases of TRG3 in NATRACE-CRT group, while 8 cases of TRG0 (pCR), 7 cases of TRG1, 17 cases TRG2, and 13 cases of TRG3 were found in the NA-CRT group. $\mathbf{b}$ It shows that the TRG0 +1 patient in NATRACE-CRT group had significantly more than patients in NA-CRT group. $\mathbf{c}$ Kaplan-Meier survival analysis of DFS in two groups, $p=0.0797$

leukopenia $(6,4.44 \%)$ and radiation proctitis (2, $2.22 \%)$; adverse events of grade $1-2$, mainly including loss of appetite $(32,40 \%)$, followed by fatigue $(24 \%$, $24.44)$, diarrhea $(24,20 \%)$, and anemia $(16,13.33 \%)$. The incidence of toxicity and side effects of grade 34 was $14 \%$ in NATRACE-CRT group and $13.33 \%$ in NA-CRT group, respectively. Moreover, there were 15 cases of radiation proctitis in the NATRACE-CRT group and 8 cases in the NA-CRT group. There were no statistically significant differences in adverse events between the two groups. The details of adverse events are shown in Table 3.

\section{Surgery-related toxicity}

Postoperative complications in the NATRACE-CRT group included incision infection (1/50), pelvic infection $(2 / 50)$, and anastomotic leakage (1/50). The complications of the NA-CRT group included pelvic infection (1/ $45)$, anastomotic leakage (1/45), and intestinal obstruction (1/45). There was no significant difference in 
Table 3 Adverse events during chemoradiotherapy $(n=95)$

\begin{tabular}{|c|c|c|c|c|c|c|}
\hline & G1 + G2 (\%) & & & G3 + G4 (\%) & & \\
\hline & NATRACE-CRT & NA-CRT & $P$-value & NATRACE-CRT & NA-CRT & $P$-value \\
\hline Leukopenia & $7(14.00)$ & $3(6.67)$ & 0.324 & $3(6.00)$ & $2(4.44)$ & 0.735 \\
\hline Neutropenia & $3(6.00)$ & $1(2.22)$ & 0.619 & $1(2.00)$ & $1(2.22)$ & 0.941 \\
\hline Anemia & $8(16.00)$ & $6(13.33)$ & 0.778 & & & \\
\hline Thrombocytopenia & $3(6.00)$ & $1(2.22)$ & 0.619 & $1(2.00)$ & $1(2.22)$ & 0.941 \\
\hline Febrile neutropenia & 0 & $1(2.22)$ & NA & & $1(2.22)$ & NA \\
\hline AST & 0 & $1(2.22)$ & NA & & & \\
\hline ALT & 0 & $1(2.22)$ & NA & & & \\
\hline Total bilirubin & $1(2.00)$ & $1(2.22)$ & 0.941 & & & \\
\hline Nausea & $15(30.00)$ & $11(24.44)$ & 0.647 & & & \\
\hline Vomiting & $4(8.00)$ & $3(6.67)$ & 0.804 & & & \\
\hline Fatigue & $12(24.00)$ & $11(24.44)$ & 0.960 & & & \\
\hline Diarrhea & $12(24.00)$ & $9(20.00)$ & 0.805 & & & \\
\hline Appetite loss & $16(32.00)$ & $18(40.00)$ & 0.521 & & & \\
\hline Hand-foot syndrome & $1(2.00)$ & 0 & NA & & & \\
\hline Radiation proctitis & $15(30.00)$ & $12(26.67)$ & 0.719 & $1(2.00)$ & $2(4.44)$ & 0.496 \\
\hline
\end{tabular}

Abbreviations: AST aspartate aminotransferase, $A L T$ alanine aminotransferase. National Cancer Institute Common Toxicity Criteria, version 4.0

operative methods and complications between the two groups. The details of surgery and surgical complications are shown in Table $\mathrm{S} 2$.

\section{Discussion}

TACE has been extensively used in the treatment of advanced hepatocellular carcinoma, possessing a satisfactory effect on local control of tumors, while it has rarely been reported in other types of tumors. Adding oxaliplatin to the regimen of adjuvant chemotherapy based on 5-FU has improved DFS and OS in colon cancer [19], Therefore, several large randomized phases III trials tested the efficacy of adding oxaliplatin to the multimodal neoadjuvant treatment for LARC. The CAO/ ARO/AIO-04 [20] study is the only one with positive results at present. STAR-01 [21], ACCORD12 [22], and NSABP-R04 [23] studies all suggested that oxaliplatin did not possess survival benefits. The interim analysis of FOWARC [24] revealed that oxaliplatin could improve the pCR rate, while the final results did not present survival benefits. In addition, several meta-analyses also suggested that the addition of oxaliplatin to neoadjuvant therapy could improve the rate of $\mathrm{pCR}$ and reduce the rate of distant metastasis [25, 26].

Several studies have found that pathological regression was correlated with local control of tumors, distant metastasis, DFS, and OS [10, 27, 28], thus we selected pathological regression as a short-time curative effect, and found that TRACE with oxaliplatin can improve the rates of pCR and TRG0 + 1, which would be comparable to FOLFOX in 6 cycles before surgery [24], and higher than that of oxaliplatin intravenous administration (14$19.2 \%)[20,21,23,29,30]$.

A series of Japan studies have found that S-1 adjuvant chemotherapy has similar efficacy to Tegafur. In addition, when $\mathrm{S}-1$ is used as a neoadjuvant therapy regimen, it can improve the $\mathrm{pCR}$ rate $[14,15]$. A metaanalysis compared the safety and efficacy of S1 or 5-FUbased chemotherapy for advanced colorectal cancer [31], which showed that no difference in OS, PFS, and ORR between the two groups, while there was lower incidence in grade 3-4 neutropenia, nausea, and vomiting with S-1 treatment. Our study found that S-1 single drug chemotherapy combined with TARCE can significantly improve the rate of pathological remission.

The adverse events of NATRACE-CRT were well tolerated. No relevant treatment-related deaths were found. The most common adverse events in grade1-2 were loss of appetite and fatigue, and diarrhea symptoms. There were no obvious neurological symptoms and skin toxicity and mucositis caused by oxaliplatin. Radiation proctitis occurred in 15 patients, while they were mostly in grade $1-2$, similar to that in the NA-CRT group. In NATRACE-CRT group, the dose of oxaliplatin was 85 $\mathrm{mg} / \mathrm{m}^{2}$, one time, which were $85 \mathrm{mg} / \mathrm{m}^{2} \times 6$ times in the FOWARC study, and $60 \mathrm{mg} / \mathrm{m}^{2} \times 6$ times in the STAR01 study. The cumulative dose of oxaliplatin was notably lower than that in previous studies, which might be related to the relatively low incidence of toxic side effects in the present study.

The NATRACE-CRT group did not increase the complications. In this study, patients in the NATRACE-CRT 
group received surgery 4 weeks after the completion of chemoradiation. Previous studies have shown that the maximum pCR rate can be achieved by $8-12$ weeks of operation interval [32-34]. Therefore, we speculate that on the basis of this study, if the operation interval is prolonged, a higher pCR rate may be obtained. The limitations of this study were small sample size and insufficient follow-up.

\section{Conclusion}

TRACE with oxaliplatin plus S-1 concurrent chemoradiotherapy as a neoadjuvant therapy provided better pathological remission rate versus standard treatment with a similar safety profile.

\section{Supplementary information}

Supplementary information accompanies this paper at https://doi.org/10. 1186/s13014-020-01540-4

Additional file 1: Table S1.1. Pathologic Response-T stage. Table S1.2. Pathologic Response-N stage. Table S2. Surgical Procedures and complications.

\section{Abbreviations}

TRACE: Transcatheter rectal arterial chemoembolization; TRG: Tumor regression grade; ORR: Objective response rate; CRT: Chemoradiotherapy; TME: Total mesorectal excision; LARC: Locally advanced rectal cancer; pCR: Pathologic complete remission; DFS: Disease-free survival; OS: Overall survival

\section{Acknowledgements}

Not applicable.

\section{Authors' contributions}

All authors contributed substantially to the work reported. CL and DW have made substantial contributions to conception and design. BY, JS was substantially involved in data acquisition and patient management. ND,ML,CC substantially involved in patient management. SH and GW were mainly responsible for performing TARCE and patient management. DW and HX performed the histological examination. BY was responsible for data curation, analyzed the data and performed statistical analyses. BY and DW was mainly responsible for data curation, interpretation and writing the manuscript. Resources and supervision were provided by DW and CL. All authors read and approved the final manuscript.

\section{Funding}

Clinical medical research personnel training program of the Army Medical University. No.2018XLC306

\section{Availability of data and materials}

Not applicable.

\section{Ethics approval and consent to participate}

The study was approved by the local Ethics Committee of Military Medical University. Written informed consent was obtained from each participant before entering the trial.

\section{Consent for publication}

Not applicable.

\section{Competing interests}

The authors declare that they have no competing interests.

\section{Author details}

'Cancer Center, Daping Hospital \& Army Medical Center of PLA, Third Military Medical University (Army Medical University), Chongqing 400042, China. ${ }^{2}$ Department of Pathology, Daping Hospital \& Army Medical Center of PLA, Third Military Medical University (Army Medical University), Chongqing 400042, China. ${ }^{3}$ Department of General Surgery, Colorectal Division, Daping Hospital \& Army Medical Center of PLA, Third Military Medical University (Army Medical University), Chongqing 400042, China.

Received: 23 November 2019 Accepted: 15 April 2020

Published online: 06 May 2020

\section{References}

1. Chen W, Zheng R, Baade PD, Zhang S, Zeng H, Bray F, Jemal A, Yu XQ, He J. Cancer statistics in China, 2015. CA Cancer J Clin. 2016;66(2):115-32.

2. Bray F, Ferlay J, Soerjomataram I, Siegel RL, Torre LA, Jemal A. Global cancer statistics 2018: GLOBOCAN estimates of incidence and mortality worldwide for 36 cancers in 185 countries. CA Cancer J Clin. 2018;68(6):394-424.

3. Kapiteijn E, Marijnen CA, Nagtegaal ID, Putter H, Steup WH, Wiggers T, Rutten HJ, Pahlman L, Glimelius B, van Krieken JH, et al. Preoperative radiotherapy combined with total mesorectal excision for resectable rectal cancer. N Engl J Med. 2001;345(9):638-46.

4. van Gijn W, Marijnen CA, Nagtegaal ID, Kranenbarg EM, Putter H, Wiggers T, Rutten HJ, Pahlman L, Glimelius B, van de Velde CJ, et al. Preoperative radiotherapy combined with total mesorectal excision for resectable rectal cancer: 12-year follow-up of the multicentre, randomised controlled TME trial. Lancet Oncol. 2011;12(6):575-82.

5. Valentini V, Coco C, Picciocchi A, Morganti AG, Trodella L, Ciabattoni A, Cellini F, Barbaro B, Cogliandolo S, Nuzzo G, et al. Does downstaging predict improved outcome after preoperative chemoradiation for extraperitoneal locally advanced rectal cancer? A long-term analysis of 165 patients. Int J Radiat Oncol Biol Phys. 2002;53(3):664-74.

6. Vecchio FM, Valentini V, Minsky BD, Padula GD, Venkatraman ES, Balducci M Micciche F, Ricci R, Morganti AG, Gambacorta MA, et al. The relationship of pathologic tumor regression grade (TRG) and outcomes after preoperative therapy in rectal cancer. Int J Radiat Oncol Biol Phys. 2005;62(3):752-60.

7. Nahas SC, Rizkallah Nahas CS, Sparapan Marques CF, Ribeiro U Jr, Cotti GC, Imperiale AR, Capareli FC, Chih Chen AT, Hoff PM, Cecconello I. Pathologic complete response in rectal Cancer: can we detect it? Lessons learned from a proposed randomized trial of watch-and-wait treatment of rectal Cancer. Dis Colon Rectum. 2016;59(4):255-63.

8. Lorimer PD, Motz BM, Kirks RC, Boselli DM, Walsh KK, Prabhu RS, Hill JS, Salo JC. Pathologic complete response rates after Neoadjuvant treatment in rectal Cancer: An analysis of the National Cancer Database. Ann Surg Oncol. 2017;24(8):2095-103.

9. Jager T, Neureiter D, Urbas R, Klieser E, Hitzl W, Emmanuel K, Dinnewitzer A. Applicability of American joint committee on Cancer and College of American Pathologists Regression Grading System in rectal Cancer. Dis Colon Rectum. 2017;60(8):815-26

10. Zorcolo L, Rosman AS, Restivo A, Pisano M, Nigri GR, Fancellu A, Melis M. Complete pathologic response after combined modality treatment for rectal cancer and long-term survival: a meta-analysis. Ann Surg Oncol. 2012 19(9):2822-32

11. Lewis AL, Holden RR. DC bead embolic drug-eluting bead: clinical application in the locoregional treatment of tumours. Expert Opin Drug Deliv. 2011:8(2):153-69.

12. Liu X, Wang Z, Chen Z, Liu L, Ma L, Dong L, Zhang Z, Zhang S, Yang L, Shi J, et al. Efficacy and safety of Transcatheter arterial chemoembolization and Transcatheter arterial chemotherapy infusion in hepatocellular carcinoma: a systematic review and Meta-analysis. Oncol Res. 2018;26(2):231-9.

13. Bini R, Comelli S, Leli R, Vaudano GP, Savio D, Viora T, Addeo A. A novel approach to inoperable or recurrent rectal cancer by chemoembolization: a new arrow in our quiver? Oncotarget. 2016;7(29):45275-82.

14. Oki E, Murata A, Yoshida K, Maeda K, Ikejiri K, Munemoto Y, Sasaki K, Matsuda C, Kotake M, Suenaga T, et al. A randomized phase III trial comparing S-1 versus UFT as adjuvant chemotherapy for stage II/III rectal cancer (JFMC35-C1: ACTS-RC). Ann Oncol. 2016:27(7):1266-72.

15. Kondo K, Matsusaka S, Ishihara S, Horie H, Uehara K, Oguchi M, Murafushi K, Ueno M, Mizunuma N, Shimbo T, et al. Long-term results of a multicenter phase II study of preoperative chemoradiotherapy with S-1 plus oxaliplatin 
for locally advanced rectal cancer (JACCRO CC-04: SHOGUN trial). Radiother Oncol. 2019;134:199-203.

16. Schwartz LH, Litiere S, de Vries E, Ford R, Gwyther S, Mandrekar S, Shankar L, Bogaerts J, Chen A, Dancey J, et al. RECIST 1.1-update and clarification: from the RECIST committee. Eur J Cancer. 2016;62:132-7.

17. Ryan R, Gibbons D, Hyland JM, Treanor D, White A, Mulcahy HE, O'Donoghue DP, Moriarty M, Fennelly D, Sheahan K. Pathological response following long-course neoadjuvant chemoradiotherapy for locally advanced rectal cancer. Histopathology. 2005;47(2):141-6.

18. Quirke P, Steele R, Monson J, Grieve R, Khanna S, Couture J, O'Callaghan C, Myint AS, Bessell E, Thompson LC, et al. Effect of the plane of surgery achieved on local recurrence in patients with operable rectal cancer: a prospective study using data from the MRC CRO7 and NCIC-CTG CO16 randomised clinical trial. Lancet. 2009;373(9666):821-8.

19. Yothers G, O'Connell MJ, Allegra CJ, Kuebler JP, Colangelo LH, Petrelli NJ, Wolmark N. Oxaliplatin as adjuvant therapy for colon cancer: updated results of NSABP C-07 trial, including survival and subset analyses. J Clin Oncol. 2011;29(28):3768-74.

20. Rödel C, Graeven U, Fietkau R, Hohenberger W, Hothorn T, Arnold D, Hofheinz R-D, Ghadimi M, Wolff HA, Lang-Welzenbach M, et al. Oxaliplatin added to fluorouracil-based preoperative chemoradiotherapy and postoperative chemotherapy of locally advanced rectal cancer (the German CAO/ARO/AIO-04 study): final results of the multicentre, open-label, randomised, phase 3 trial. Lancet Oncol. 2015;16(8):979-89.

21. Aschele C, Cionini L, Lonardi S, Pinto C, Cordio S, Rosati G, Artale S, Tagliagambe A, Ambrosini G, Rosetti P, et al. Primary tumor response to preoperative chemoradiation with or without oxaliplatin in locally advanced rectal cancer: pathologic results of the STAR-01 randomized phase III trial. J Clin Oncol. 2011;29(20):2773-80.

22. Gerard JP, Azria D, Gourgou-Bourgade S, Martel-Lafay I, Hennequin C, Etienne PL, Vendrely V, Francois E, de La Roche G, Bouche O, et al. Clinical outcome of the ACCORD 12/0405 PRODIGE 2 randomized trial in rectal cancer. J Clin Onco. 2012;30(36):4558-65.

23. O'Connell MJ, Colangelo LH, Beart RW, Petrelli NJ, Allegra CJ, Sharif S, Pitot HC, Shields AF, Landry JC, Ryan DP, et al. Capecitabine and oxaliplatin in the preoperative multimodality treatment of rectal cancer: surgical end points from National Surgical Adjuvant Breast and bowel project trial R-04. J Clin Oncol. 2014:32(18):1927-34.

24. Deng Y, Chi P, Lan P, Wang L, Chen W, Cui L, Chen D, Cao J, Wei H, Peng X, et al. Modified FOLFOX6 with or without radiation versus fluorouracil and Leucovorin with radiation in Neoadjuvant treatment of locally advanced rectal Cancer: initial results of the Chinese FOWARC multicenter, open-label, randomized three-arm phase III trial. J Clin Oncol. 2016;34(27):3300-7.

25. De Felice F, Benevento I, Magnante AL, Musio D, Bulzonetti N, Caiazzo R, Tombolini V. Clinical benefit of adding oxaliplatin to standard neoadjuvant chemoradiotherapy in locally advanced rectal cancer: a meta-analysis : Oxaliplatin in neoadjuvant treatment for rectal cancer. BMC Cancer. 2017; 17(1):325.

26. An X, Lin X, Wang FH, Goodman K, Cai PQ, Kong LH, Fang YJ, Gao YH, Lin $J Z$, Wan DS, et al. Short term results of neoadjuvant chemoradiotherapy with fluoropyrimidine alone or in combination with oxaliplatin in locally advanced rectal cancer: a meta analysis. Eur J Cancer. 2013;49(4):843-51.

27. Maas MNP, Valentini V, Das P, Rödel C, Kuo LJ, Calvo FA, García-Aguilar J, Glynne-Jones R, Haustermans K, Mohiuddin M, Pucciarelli S, Small W Jr, Suárez J, Theodoropoulos G, Biondo S, Beets-Tan RG, Beets GL. Long-term outcome in patients with a pathological complete response after chemoradiation for rectal cancer: a pooled analysis of individual patient data. Lancet Oncol. 2010;11(9):9.

28. Ortholan C, Romestaing P, Chapet O, Gerard JP. Correlation in rectal cancer between clinical tumor response after neoadjuvant radiotherapy and sphincter or organ preservation: 10-year results of the Lyon R 96-02 randomized trial. Int J Radiat Oncol Biol Phys. 2012;83(2):e165-71.

29. Gerard JP, Azria D, Gourgou-Bourgade S, Martel-Laffay I, Hennequin C, Etienne PL, Vendrely V, Francois E, de La Roche G, Bouche O, et al. Comparison of two neoadjuvant chemoradiotherapy regimens for locally advanced rectal cancer: results of the phase III trial ACCORD 12/0405Prodige 2. J Clin Oncol. 2010;28(10):1638-44.

30. Schmoll HJ, Haustermans K, Price T, Nordlinger B, Hofheinz R, Daisne JF, Janssens J, Brenner B, Schmidt P, Reinel H, et al. O-0017preoperative Chemoradiotherapy and Postoperative Chemotherapy with Capecitabine and
Oxaliplatin Vs. Capecitabine Alone in Locally Advanced Rectal Cancer: Disease Free Survival at Interim Analysis. Ann Oncol. 2014;25(suppl_2):ii111-2.

31. Ye J, Chen J, Ge L, Liu A, Zhou S. Effectiveness and safety of s-1-based therapy compared with 5-fluorouracil-based therapy for advanced colorectal cancer: a meta-analysis. Gastroenterol Res Pract. 2014;2014: 146530.

32. Petrelli F, Sgroi G, Sarti E, Barni S. Increasing the interval between Neoadjuvant Chemoradiotherapy and surgery in rectal Cancer: a Metaanalysis of published studies. Ann Surg. 2016;263(3):458-64.

33. Sloothaak DAM, Geijsen DE, van Leersum NJ, Punt CJA, Buskens CJ, Bemelman WA, Tanis PJ. Optimal time interval between neoadjuvant chemoradiotherapy and surgery for rectal cancer. Br J Surg. 2013;100(7): 933-9.

34. Macchia G, Gambacorta MA, Masciocchi C, Chiloiro G, Mantello G, di Benedetto M, Lupattelli M, Palazzari E, Belgioia L, Bacigalupo A, et al. Time to surgery and pathologic complete response after neoadjuvant chemoradiation in rectal cancer: a population study on 2094 patients. Clin Transl Radiat Oncol. 2017;4:8-14.

\section{Publisher's Note}

Springer Nature remains neutral with regard to jurisdictional claims in published maps and institutional affiliations.

\section{Ready to submit your research? Choose BMC and benefit from:}

- fast, convenient online submission

- thorough peer review by experienced researchers in your field

- rapid publication on acceptance

- support for research data, including large and complex data types

- gold Open Access which fosters wider collaboration and increased citations

- maximum visibility for your research: over $100 \mathrm{M}$ website views per year

At BMC, research is always in progress.

Learn more biomedcentral.com/submissions 